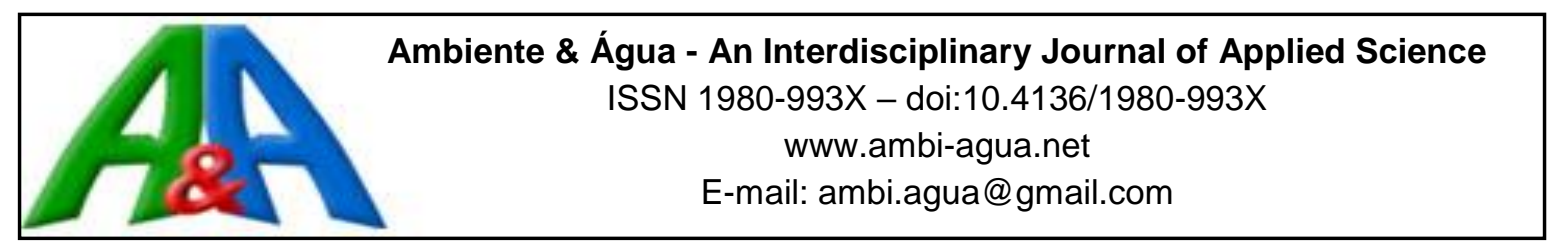

\title{
Análise da renovação das águas do Sistema Estuarino de Santos usando modelagem computacional
}

\author{
doi:10.4136/ambi-agua.1770
}

Received: 02 Oct. 2015; Accepted: 16 May 2016

\author{
Fernando Roversi $^{1 *}$; Paulo Cesar Colonna Rosman ${ }^{1}$; Joseph Harari ${ }^{2}$ \\ ${ }^{1}$ Universidade Federal do Rio de Janeiro (COPPE/UFRJ), Rio de Janeiro, RJ, Brasil \\ Programa de Engenharia Oceânica/Área de Engenharia Costeira e Oceanográfica \\ ${ }^{2}$ Universidade de São Paulo (IO-USP), São Paulo, SP, Brasil \\ Instituto Oceanográfico \\ "Autor correspondente: e-mail: fernandoroversi@gmail.com, \\ pccrosman@ufrj.br, joharari@usp.br
}

\section{RESUMO}

A investigação de processos inerentes a um sistema estuarino permite inferir de forma mais precisa sua complexa dinâmica, possibilitando o balizamento de estratégias de ação em planos de gestão e projetos ambientais em regiões costeiras. Este trabalho apresenta um estudo da hidrodinâmica do Sistema Estuarino de Santos (SP), com enfoque na análise da renovação de suas águas, pelo efeito da maré e pelas vazões fluviais afluentes. Por meio do SisBaHiA $^{\circledR}$ (Sistema Base de Hidrodinâmica Ambiental) foi implementado um modelo hidrodinâmico computacional para a reprodução dos padrões de circulação do sistema. A partir de simulações com o Modelo de Transporte Euleriano, foram então calculadas as taxas de renovação de suas águas, para os períodos representativos de verão e de inverno. Os resultados, apresentados na forma de mapas e na forma de séries temporais de renovação, indicaram que após 30 dias todo o sistema apresenta uma renovação total maior que $95 \%$. Diferenças sazonais puderam ser verificadas apenas em regiões mais internas do estuário, e.g., no Canal de Piaçaguera.

Palavras-chave: hidrodinâmica, modelagem de circulação, SisBaHiA ${ }^{\circledR}$.

\section{Water renewal analysis of the Santos Estuarine System using computational modeling}

\begin{abstract}
The investigation of processes inherent in an estuary system allows us to infer more precisely its complex dynamics, assisting in the development of action strategies for environmental management plans and projects in coastal areas. This paper describes a hydrodynamic study of the Santos Estuarine System (São Paulo State, Brazil), focused on its water renewal analysis. A computational model was implemented using SisBaHiA ${ }^{\circledR}$ (Base System for Environmental Hydrodynamics) in order to reproduce the hydrodynamic patterns of the system. Simulations based on Eulerian Transport Model were performed to compute renewal rates for summer and winter representative periods. Results presented on maps and time series indicated that after 30 days the entire system has a total renewal greater than $95 \%$.
\end{abstract}


Seasonal differences could only be verified on the inner regions of the estuary, such as Piaçaguera Channel.

Keywords: circulation modeling, hydrodynamics, SisBaHiA ${ }^{\circledR}$.

\section{INTRODUÇÃO}

O Sistema Estuarino de Santos localiza-se na Região Metropolitana da Baixada Santista (RMBS), litoral do Estado de São Paulo (Figura). A RMBS é formada por nove municípios, com um total de aproximadamente 1,8 milhão de habitantes fixos, distribuídos em $2.420 \mathrm{~km}^{2}$ (IBGE, 2015). A expressiva atividade industrial do Município de Cubatão e a grande movimentação de embarcações no Porto de Santos são alguns dos fatores que caracterizaram a RMBS como um dos maiores exemplos brasileiros de degradação ambiental por poluição hídrica em ambientes costeiros (CETESB, 2001). A intensa ocupação que se espalhou ao redor da Ilha de São Vicente, desde meados do século XIX, acarretou severos danos ambientais à região. A poluição dos corpos d'água pelo lançamento de efluentes in natura e de resíduos sólidos; a degradação dos mangues; a diminuição da quantidade das águas disponíveis para consumo; a redução do índice de balneabilidade das praias; e, ainda, as ocupações irregulares de encostas, de mananciais, das margens de rios e de manguezais, foram alguns dos aspectos que estiveram associados a esse processo de urbanização (Zündt, 2006). Resultados do monitoramento ambiental realizado pela CETESB (2010) mostraram baixos índices de qualidade das águas do Sistema Estuarino de Santos, indicando um cenário de: "Depleção de Oxigênio Dissolvido (OD); Incremento de nutrientes (compostos de Nitrogênio e Fósforo) e de matéria orgânica (Demanda Bioquímica de Oxigênio - DBO); e, ainda, presença de microrganismos indicadores de poluição fecal (Coliformes Termotolerantes)".

Situado numa região de Planície Costeira, limitada pelo Oceano Atlântico e pelas escarpas da Serra do Mar, o Sistema Estuarino de Santos apresenta uma configuração morfológica bastante complexa, com múltiplas cabeceiras, extensas áreas alagáveis com formação de manguezais e bancos de lama, e também diferentes ligações com o oceano adjacente. Seu sistema hidrográfico pode ser subdivido em três estuários e uma baía: o Estuário do Canal de Bertioga, com extremidades entre os municípios de Guarujá e Bertioga, dividindo a Ilha de Santo Amaro da planície costeira continental; o Estuário do Canal do Porto de Santos e o Estuário de São Vicente, ambos com suas embocaduras na Baía de Santos no entorno da Ilha de São Vicente (Figura 1).

Assim como a geometria intrincada dos canais, efeitos oceanográficos, hidrológicos e meteorológicos são fatores complexos que definem o escoamento das águas e o transporte de poluentes e de outros constituintes pelo sistema. Para uma melhor investigação e representação desses fenômenos dinâmicos, a técnica de modelagem computacional constitui metodologia de grande potencial, conforme já verificado em outros trabalhos, como por exemplo: Harari e Camargo (1994) simularam a propagação das principais componentes de maré ao longo da plataforma sudeste brasileira; Harari e Camargo (1998) simularam a circulação de maré para a região costeira de Santos; Yassuda (1991) implementou um modelo para o cálculo do transporte de sedimentos no canal do Porto de Santos; Gordon (2000) modelou a dispersão de substâncias nos canais interiores do estuário; Chambel e Mateus (2008) implementaram um modelo hidrodinâmico para o estuário e analisaram tempos de residência de alguns compartimentos do sistema; Baptistelli (2008) apresentou uma análise crítica comparando a utilização de diferentes modelos computacionais para representação da hidrodinâmica da região; Gregório (2009) modelou a dispersão da pluma de efluente do emissário submarino de Santos; Sampaio (2010) modelou a dispersão de efluentes domésticos 
lançados através de diferentes fontes de poluição urbana identificadas na região; Ribeiro (2012) analisou a influência das concentrações de nutrientes sobre a variabilidade da biomassa fitoplanctônica presente no sistema, por meio da modelagem hidrodinâmica e de qualidade de água; Roversi et al. (2016) apresentaram uma análise das trajetórias das águas continentais afluentes ao sistema. Porém nenhum desses trabalhos analisou especificamente a renovação das águas do sistema.

O presente estudo tem como objetivo apresentar uma análise de taxas de renovação das águas do Sistema Estuarino de Santos, utilizando como ferramenta base a modelagem computacional.

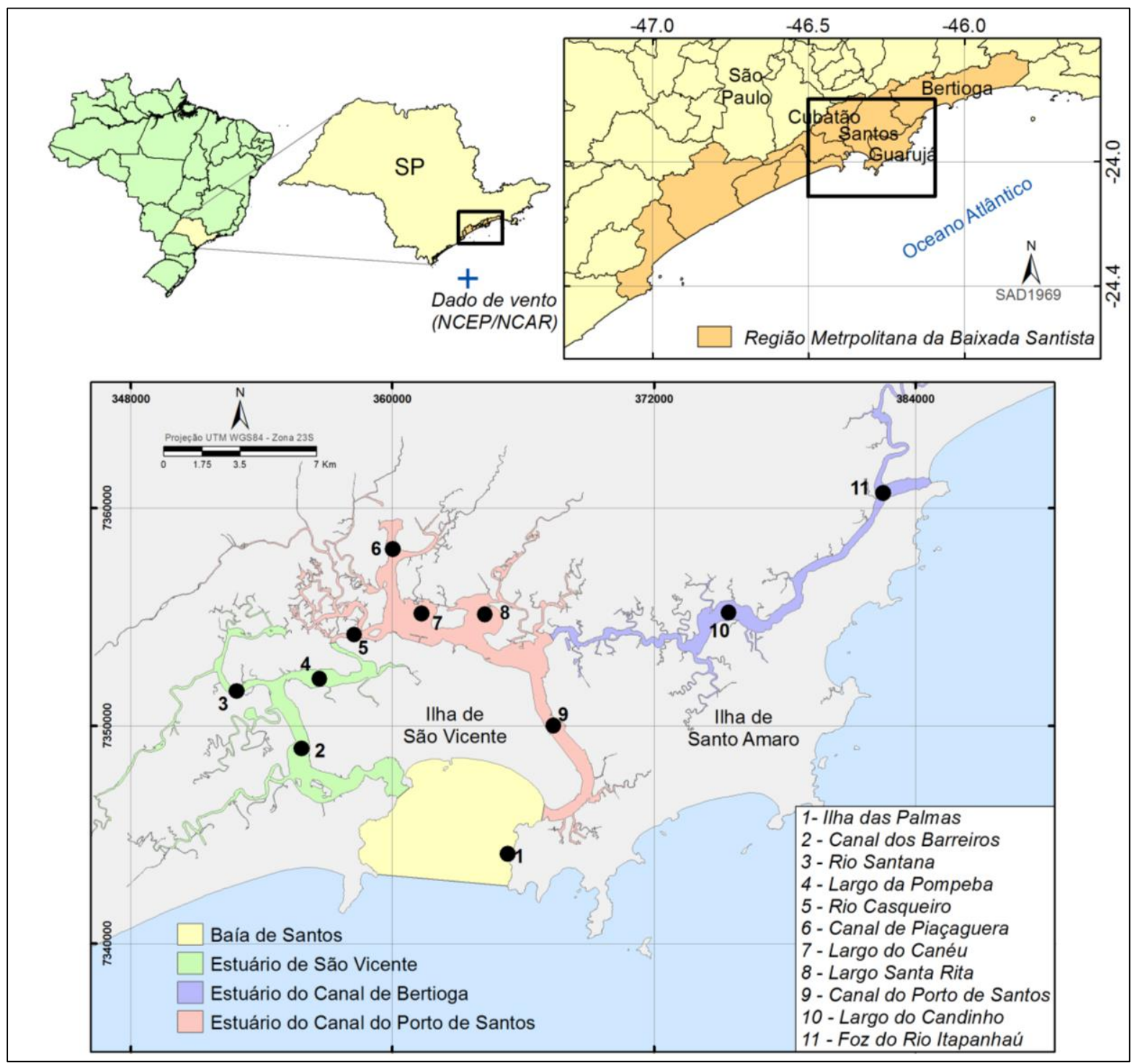

Figura1. Localização do Sistema Estuarino de Santos e seus subsistemas hidrográficos.

\section{METODOLOGIA}

\subsection{Modelo hidrodinâmico e de transporte de propriedades}

As simulações computacionais foram realizadas por meio do $\mathrm{SisBaHiA}^{\circledR}$ (Sistema Base de Hidrodinâmica Ambiental): um sistema profissional de modelos computacionais, registrado pela Fundação Coppetec (órgão gestor de convênios e contratos de pesquisa da COPPE/UFRJ), desenvolvido para projetos, estudos e gestão ambiental de recursos hídricos. 
O SisBaHiA ${ }^{\circledR}$ pode ser aplicado em simulações de cenários em águas costeiras, baías, estuários, rios, canais, reservatórios, lagos ou lagoas, visando o estudo da dinâmica de processos nestes complexos sistemas ambientais (Rosman, 2015). Os seguintes módulos do SisBaHiA ${ }^{\circledR}$ foram utilizados no presente estudo:

\section{Modelo Hidrodinâmico 2DH:}

Trata-se de um modelo hidrodinâmico da linhagem FIST (Filtered in Space and Time), otimizado para corpos d'água naturais com escoamento pouco sensível à baroclinicidade vertical (Rosman, 2015). Dentro da formulação matemática utilizada destacam-se as seguintes características:

- Resolve as equações completas de "Navier-Stokes”, considerando a aproximação de águas rasas (aproximação de pressão hidrostática) e a aproximação de "Boussinesq";

- Aplica a modelagem da turbulência baseada em técnicas de filtragem semelhantes às empregadas na Simulação de Grandes Vórtices (LES - Large Eddy Simulation);

- Utiliza a Equação de Estado, segundo a “Fórmula de Eckart”;

- No Módulo 2DH as equações da conservação da quantidade de movimento e a equação da continuidade são promediadas na vertical (escoamento bidimensional).

A formulação numérica do modelo hidrodinâmico emprega o Método dos Elementos Finitos com elementos sub-paramétricos Lagrangeanos biquadráticos, para a discretização espacial horizontal. A discretização temporal é feita por meio de esquema numérico implícito de diferenças finitas. Os efeitos de alagamento e secamento do domínio foram modelados pelo Método Poroso-Rugoso (Rosman, 2015). O passo de tempo adotado nas simulações hidrodinâmicas foi de 15 segundos, com um Número de Courant máximo igual a 4,5.

\section{Modelo de Transporte Euleriano}

Trata-se de um modelo para a simulação do transporte advectivo e difusivo de propriedades presentes no escoamento, podendo incluir ainda reações cinéticas de produção e consumo do constituinte de interesse. Quando o constituinte é ativo, por exemplo o sal, o estudo do transporte do constituinte é um problema acoplado à modelagem hidrodinâmica, pois sua presença interfere nas características do escoamento; porém, quando o constituinte é passivo a solução é desacoplada (Rosman, 1997). O modelo de transporte utiliza princípios de filtragem da linhagem FIST, semelhantes aos adotados para a modelagem hidrodinâmica (Rosman, 2015).

Na modelagem Euleriana o transporte bidimensional, promediado na vertical, de um constituinte qualquer é determinado pela seguinte equação matemática:

$$
\begin{aligned}
& \frac{\partial \hat{C}}{\partial t}+\hat{u}_{i} \frac{\partial \hat{C}}{\partial x_{i}}=\frac{1}{H} \frac{\partial}{\partial x_{i}}\left(H \hat{D}_{i j}^{T} \frac{\partial \hat{C}}{\partial x_{j}}\right)+\sum R_{P \& C} \\
& +\frac{1}{H}\left(q_{p}\left(C_{p}-\hat{C}\right)-q_{e}\left(C_{e}-\hat{C}\right)\right) \\
& +\frac{1}{H}\left(q_{i n}\left(C_{i n}-\hat{C}\right)-q_{e x}\left(C_{e x}-\hat{C}\right)\right)
\end{aligned}
$$

em que:

$\hat{C}$ é a concentração do constituinte média na coluna d'água; 
$\hat{u}_{i}$ é a componente do vetor velocidade na direção $i$ promediada na vertical;

$\boldsymbol{H}$ é altura da coluna d'água,

$\hat{\boldsymbol{D}}_{i j}^{T}$ é o tensor de difusividade turbulenta, modelado com coeficientes tipo Elder (Fischer, 1979 apud Rosman, 2015);

$\boldsymbol{R}_{P \& C}$ são reações cinéticas de produção e consumo;

$\boldsymbol{q}_{p}, \boldsymbol{q}_{e}, \boldsymbol{q}_{i n}$ e $\boldsymbol{q}_{e x}$ são vazões por unidade de área, para precipitação, evaporação, infiltração e exfiltração, respectivamente.

No presente estudo foi utilizado o modelo de transporte Euleriano de sal, acoplado à hidrodinâmica, e um modelo de transporte Euleriano para um constituinte passivo e conservativo, para o cálculo das taxas de renovação. O passo de tempo adotado para as simulações de transporte foi de 60 segundos.

\subsection{Domínio de modelagem}

As fronteiras do modelo foram definidas por meio de: imagens de satélite do "Google Earth "; mapeamentos das áreas de manguezal e dos bancos de lama do estuário (Cantagallo, 2008; Cunha, 2009; Perinotto, 2010); e Cartas Náuticas da DHN - Diretoria de Hidrografia e Navegação - Marinha do Brasil. A discretização espacial do domínio de modelagem foi realizada por meio de uma malha de elementos finitos, representando as principais feições do espelho d'água do Sistema Estuarino de Santos. A construção da malha considerou a geometria intrincada dos vários canais e das áreas alagáveis, como os manguezais e os bancos de lama. As informações referentes à batimetria da região foram extraídas das Cartas náuticas da DHN ( $n^{\circ} 1711$ e $\left.n^{\circ} 1701\right)$ e também de levantamentos batimétricos efetuados pelo CTH Centro Tecnológico de Hidráulica e Recursos Hídricos - Escola Politécnica da USP (CTH, 1976; 1968), para áreas onde as Cartas Náuticas não apresentam informações - e.g., Estuário de São Vicente. Nos limites inferior e superior das regiões alagáveis as cotas foram definidas como sendo, respectivamente, os níveis médios das baixa-mares e das preamares de sizígia. Foi considerado que o domínio como um todo é caracterizado por um leito com transporte de sedimentos, cujos valores típicos de rugosidade equivalente $(\varepsilon)$ para esse tipo de fundo situam-se na faixa de 0,01 m a 0,05 m (Abbot e Basco, 1989 apud Rosman, 2015). Devido à falta de um detalhamento da granulometria dos sedimentos existentes em cada região modelada, foi então adotado um valor médio de $\varepsilon$ igual a $0,02 \mathrm{~m}$, uniforme para todo o domínio, representativo da região, cuja predominância é de sedimentos finos. Ressalta-se ainda que a o efeito da rugosidade que atua no escoamento varia dinamicamente no tempo e no espaço, em função da coluna d'água existente em cada nó, em cada instante (Rosman, 2015).

A Figura 2 apresenta o domínio de modelagem com a malha construída e a Figura 3 apresenta o mapa batimétrico do domínio.

\subsection{Forçantes do modelo}

Como condição de contorno para a fronteira aberta do domínio foi prescrita uma série temporal de elevação da superfície livre, construída a partir das constantes harmônicas calculadas pela Fundação de Estudos do Mar (FEMAR, 2000), para a Estação Ilha das Palmas (localização apresentada na Figura 1). Todos os nós da malha computacional pertencentes à fronteira aberta receberam os mesmos valores, considerando um ajuste de amplitudes e uma defasagem no tempo para cada nó, garantindo a propagação da maré de forma condizente com os dados medidos. Esta defasagem na propagação da maré ao longo do domínio foi calculada 
a partir do trabalho de Harari e Camargo (1994).

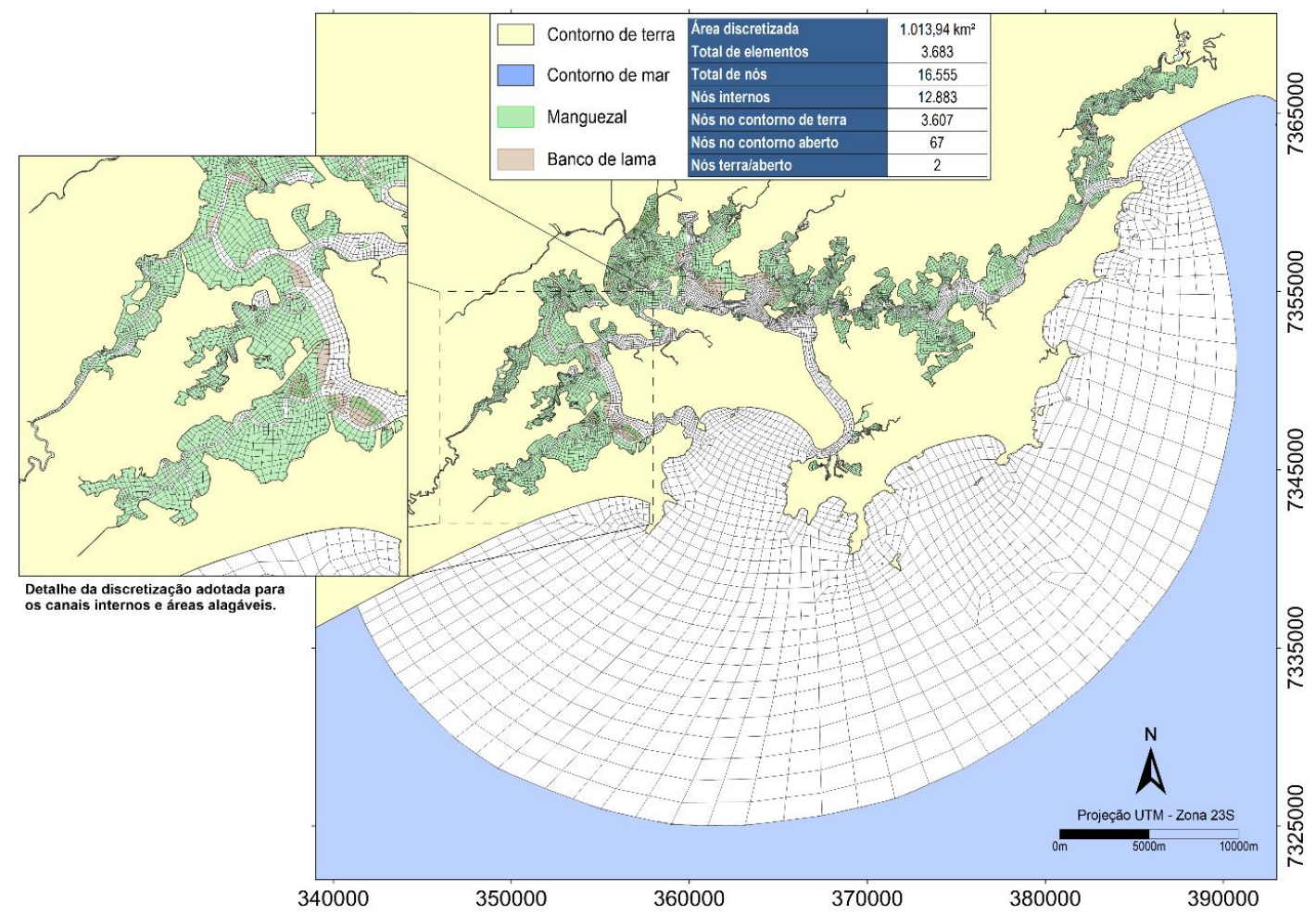

Figura 2. Malha utilizada para a discretização espacial do domínio de modelagem.

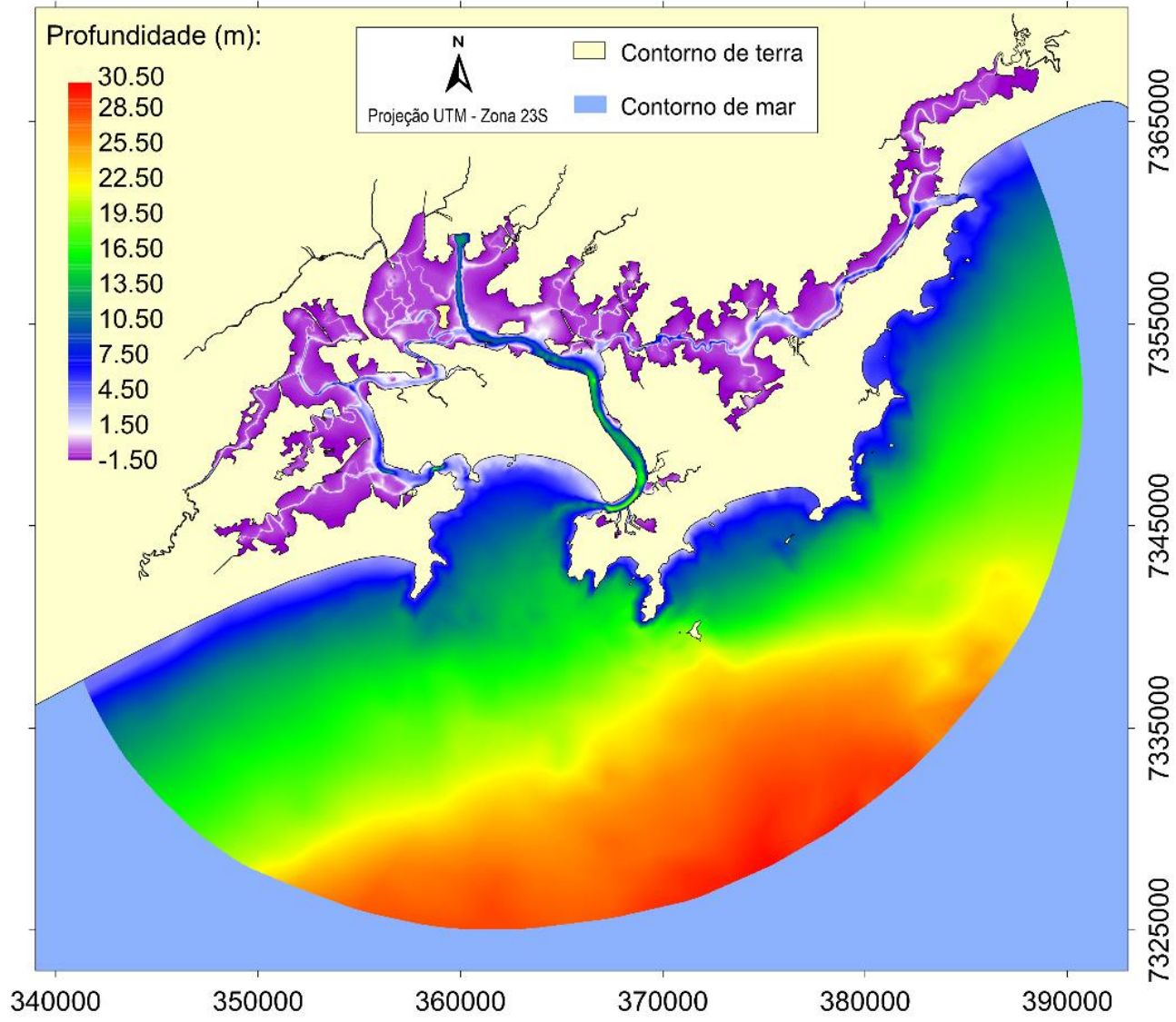

Figura 3. Batimetria utilizada no domínio de modelagem. 
Para representar condições típicas de verão, caracterizado como um período chuvoso, e de inverno, caracterizado como um período de estiagem, foram utilizadas as vazões fluviais médias de longo período $\left(\mathrm{Q}_{\mathrm{LP}}\right)$ e as vazões $\mathrm{Q}_{7,10}$, respectivamente. Os dados foram extraídos dos estudos hidrológicos apresentados no "Relatório de Situação dos Recursos Hídricos da Bacia Hidrográfica da Baixada Santista” (SHS, 2007). A vazão turbinada da usina hidroelétrica Henry Borden, lançada no rio Cubatão, foi considerada constante e igual a $6 \mathrm{~m}^{3} / \mathrm{s}$ (Ragnev, 2005). Na Figura 4 são apresentados os valores e as posições das descargas fluviais inseridas no modelo hidrodinâmico.

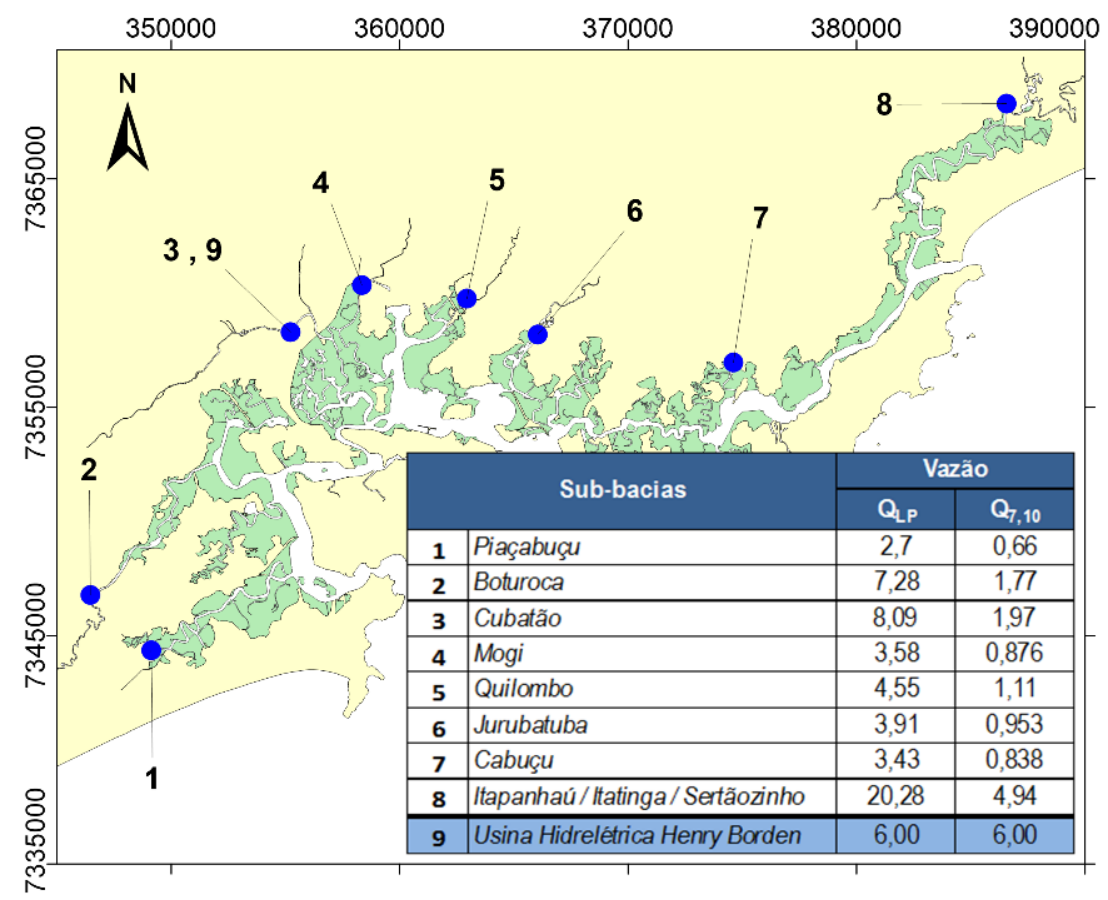

Figura 4. Descargas fluviais inseridas no modelo hidrodinâmico.

A salinidade foi modelada como um constituinte ativo no escoamento. $\mathrm{O}$ sal, ao ser transportado pelos processos de advecção e de difusão, pode alterar a densidade da água e criar gradientes horizontais de pressão que contribuem para a circulação hidrodinâmica local. Para o modelo de transporte de sal foram prescritas as seguintes condições de contorno: 35,0 psu para afluxo através da fronteira aberta (contorno de mar) e 0,0 psu para vazões continentais afluentes. Padrões de distribuição espacial de salinidade típicos de verão e de inverno, obtidos com simulações de cinco meses de duração (Roversi, 2012), foram utilizados como condições iniciais das simulações.

$\mathrm{O}$ efeito do vento foi considerado apenas durante a calibração do modelo. Os valores, utilizados de forma homogênea no domínio, basearam-se numa série temporal de vento a 10 metros de altura, gerada pelo modelo global atmosférico do projeto "Reanalysis" (Kalnay et al., 1996) do NCEP/NCAR "(National Centers for Environmental Prediction / National Center for Atmospheric Research)", extraída na coordenada geográfica do modelo mais próxima da região: $46,875^{\circ} \mathrm{S} ; 25,7139^{\circ} \mathrm{O}$ (Figura 1). Para os demais cenários hidrodinâmicos, não foi considerado o efeito do vento na superfície.

Os cenários hidrodinâmicos reproduzidos para análise da renovação das águas consideraram a combinação dos efeitos da maré astronômica, das vazões fluviais afluentes (representativas de verão e de inverno) e do gradiente horizontal de salinidade, sendo este gerado pela mistura das águas continentais com águas provenientes da região costeira. Não foram consideradas datas específicas, foram utilizadas condições genéricas típicas, representativas de verão e de inverno. As forçantes (citadas em ordem de relevância) 
predominam sobre o escoamento local e são responsáveis pelas condições de circulação hidrodinâmica mais frequentes. Na ausência de efeitos meteorológicos significativos, a circulação de maré, isoladamente, pode ser considerada como uma aproximação adequada da circulação local (Harari e Camargo, 1998).

Foi considerado um período de 90 dias de simulação, utilizando resultados dos cenários hidrodinâmicos repetidos em ciclos. A Figura 5 mostra o período de 30 dias, representado pela curva de elevação do nível d'água calculada pelo modelo na Estação Conceiçãozinha, repetido três vezes (elevações referenciadas ao Nível de Redução da DHN). Os trinta dias simulados em cada cenário compreendem dois períodos de maré de sizígia e de quadratura que são repetidos continuamente, de forma que haja uma transição suave entre os ciclos. A reprodução dos cenários hidrodinâmicos em ciclos diminuiu consideravelmente o tempo de processamento e o volume de resultados armazenados.

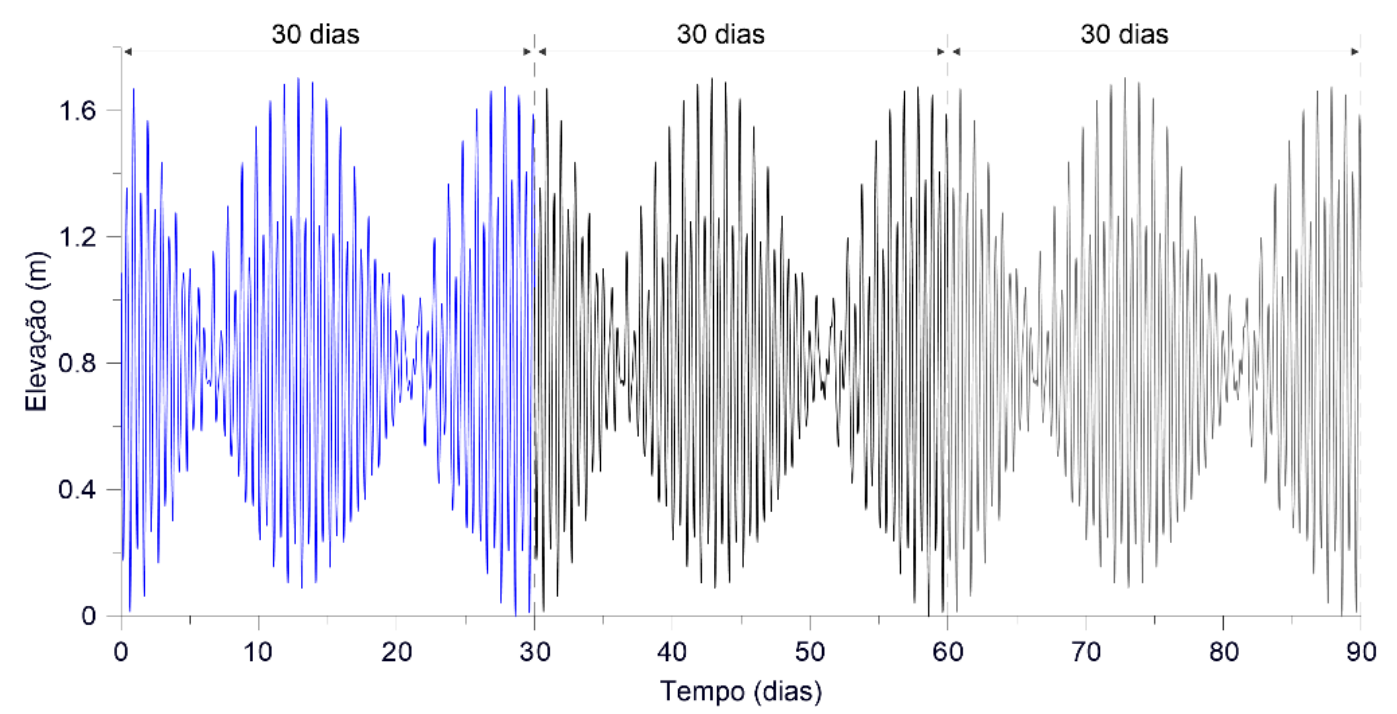

Figura 5. Cenário hidrodinâmico de 30 dias reproduzido em ciclos.

\subsection{Dados de calibração}

O modelo foi calibrado com cenários datados, utilizando os seguintes dados:

i) séries de elevação da superfície livre, medidas em quatro estações maregráficas da DHN, do dia 01 ao dia 15 de maio de 2004 (FRF, 2008);

ii) velocidades, obtidas via ADCP instalado na Ilha das Palmas, durante o mês de fevereiro de 2010; e

iii) salinidade da água, medida durante duas campanhas de monitoramento ambiental, realizadas nos meses de janeiro e de agosto de 2011 (SABESP, 2011).

\subsection{Cálculo das taxas de renovação}

As taxas de renovação das águas do Sistema Estuarino de Santos foram calculadas por meio de simulações com o Modelo de Transporte Euleriano do SisBaHiA ${ }^{\circledR}$. As simulações consideraram um constituinte conservativo sendo transportado pelos processos de advecção e de difusão ao longo do domínio, durante um período de 90 dias, paras os cenários de circulação hidrodinâmica representativos de verão e de inverno.

No instante inicial a água interna à região de interesse foi marcada com valor de referência igual a zero e a água fora dessa região com valor igual 100, conforme condição apresentada na Figura 6. Para qualquer volume de água adicionado ao domínio também foi prescrito valor de referência igual a 100, isto é, as vazões fluviais afluentes e também o afluxo através da fronteira aberta na região costeira receberam valores de referência iguais a 100. 
Essa suposição permitiu quantificar a renovação das águas do sistema, uma vez que os valores de referência, calculados ao longo das simulações, são então interpretados como porcentagem de água "nova" que adentrou a região de interesse. Análises para a renovação proporcionada pelo efeito da maré e pelo aporte fluvial, isoladamente, podem ser verificadas em Roversi (2012).

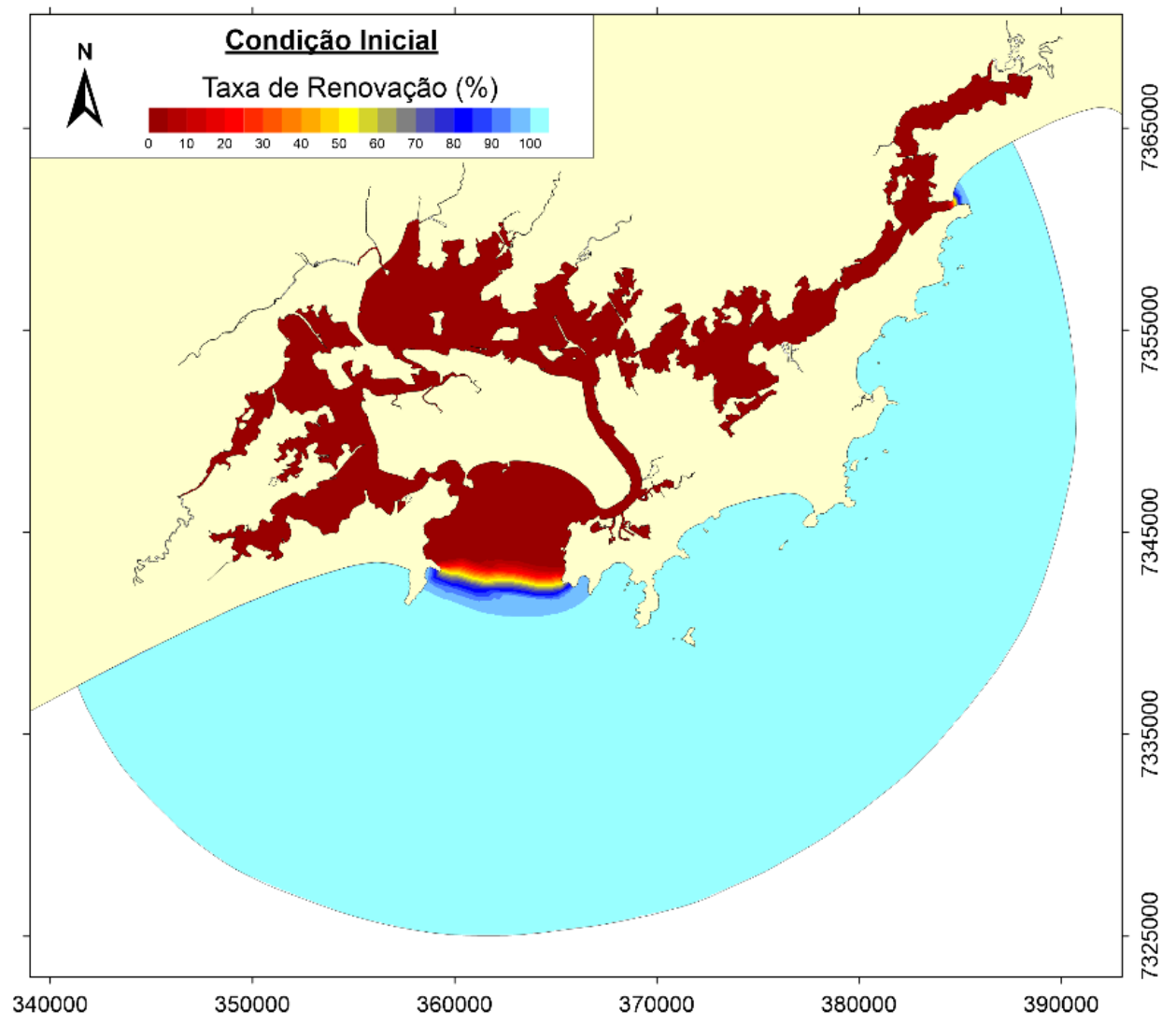

Figura 6. Condição inicial utilizada nas simulações de renovação das águas do Sistema Estuarino de Santos.

\section{RESULTADOS E DISCUSSÃO}

Nesta seção são apresentados os resultados da modelagem da circulação hidrodinâmica e da modelagem do transporte, incluindo resultados da calibração do modelo. São analisadas em maior detalhe as taxas de renovação das águas do Sistema Estuarino de Santos.

\subsection{Calibração do modelo}

O modelo representou as principais características hidrodinâmicas da região, assim como o transporte de sal. As velocidades calculadas se ajustaram à magnitude média na coluna d'água e à direção predominante das correntes registradas pelo ADCP (Figura 7). Na Figura 8 são apresentados em maior detalhe os resultados da calibração de níveis d'água. Nota-se que o modelo apresentou uma melhor aderência com a série de nível d'água medida na Estação Maregráfica Conceiçãozinha, localizada na entrada do Canal do Porto de Santos. Nas demais estações, localizadas nas regiões mais internas do estuário, os resultados apresentaram um ajuste menos preciso. Tal resultado está relacionado com a qualidade das informações batimétricas fornecidas ao modelo. Nas regiões mais próximas ao Canal do Porto há uma maior precisão na batimetria inserida, ao passo que, nas regiões mais internas do domínio, incluindo principalmente as áreas alagáveis, há uma maior incerteza nos valores de 
profundidade prescritos.

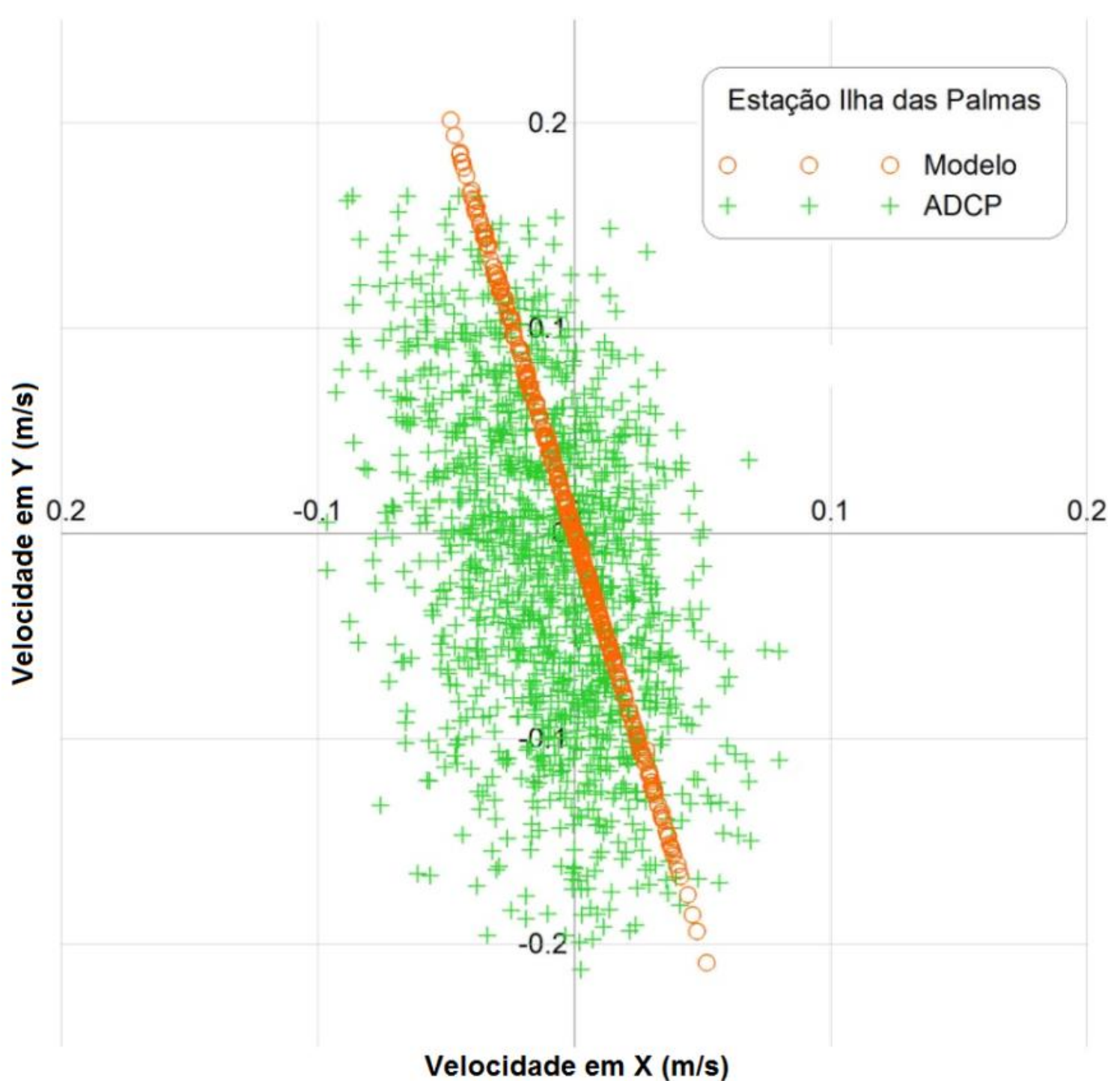

Figura 7. Correntes calculadas pelo modelo hidrodinâmico e correntes medidas via ADCP, próximo à Ilha das Palmas $\left(24^{\circ} 0^{\prime} 45^{\prime \prime} \mathrm{S} ; 4^{\circ} 19^{\prime} 35^{\prime \prime} \mathrm{W}\right)$, durante o mês de fevereiro de 2010.

Como não existem séries continuas de salinidade medidas simultaneamente às demais forçantes do modelo hidrodinâmico e ao longo de todo o período de simulação, os resultados obtidos foram então confrontados com padrões espaciais de salinidade verificados em dois conjuntos de amostras disponíveis: uma realizada em janeiro de 2011, mês representativo de verão, e outra em agosto de 2011, mês representativo de inverno (SABESP, 2011). Verificouse que a salinidade calculada pelo modelo foi capaz de capturar os padrões de distribuição espacial da região, apresentando valores próximos aos amostrados. Melhores resultados do modelo foram verificados na Baía de Santos e na embocadura do Canal do Porto, apresentando diferença máxima de 1,0 psu em relação às medições. Maior diferença pôde ser verificada na região do Canal Barreiros, apresentando diferença de até 13,0 psu. Resultados do modelo relativamente maiores que os valores medidos indicam que as vazões fluviais afluentes a essa região podem ter sido subestimadas. Na Figura 9 é ilustrada a distribuição de salinidade no instante de mínima intrusão salina (vazante) calculado pelo modelo, para o período representativo de verão. Maiores detalhes dos resultados de salinidade 
alcançados pelas simulações podem ser verificados em Roversi (2012).
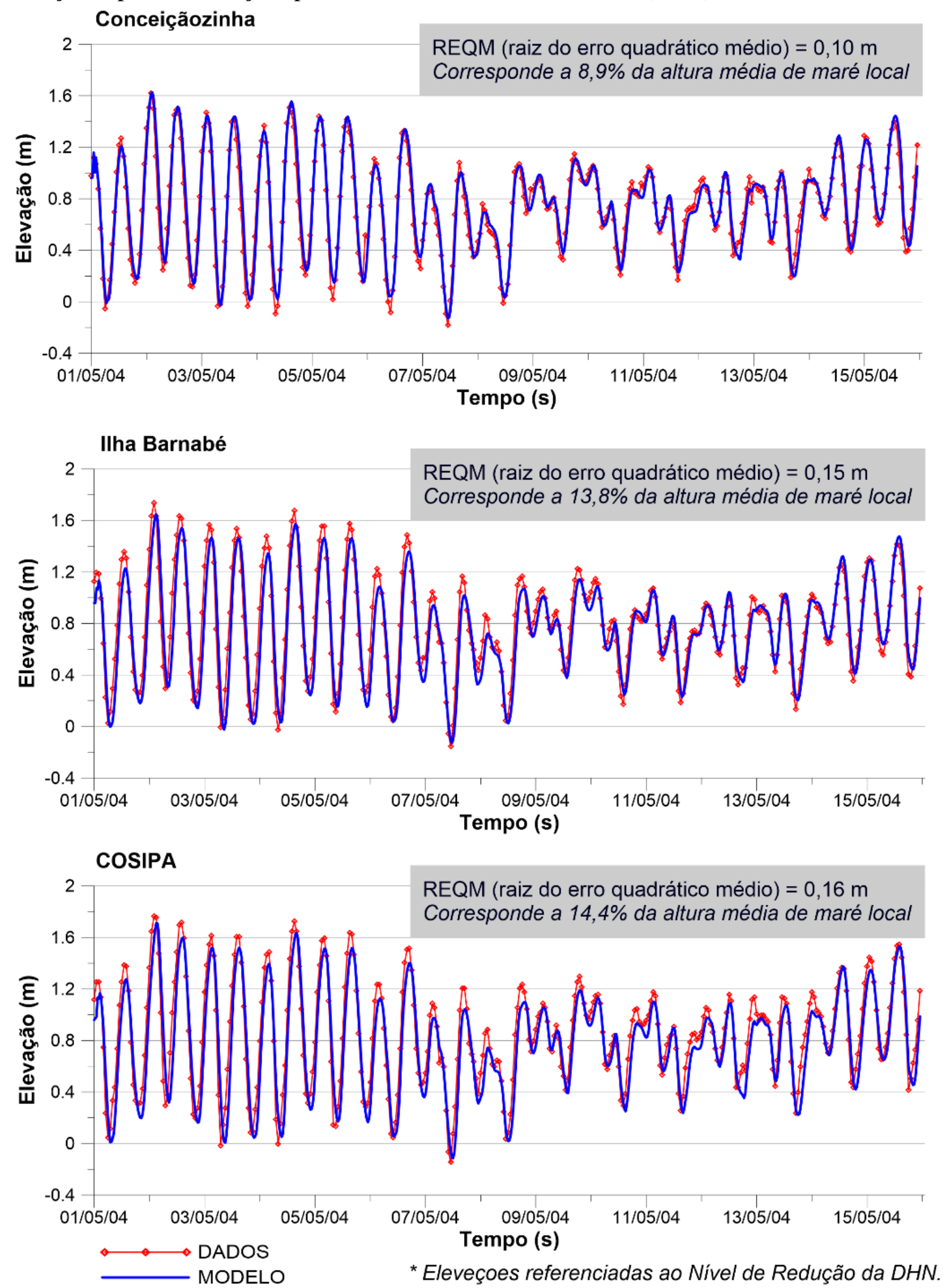

Figura 8. Níveis d'água calculados pelo modelo hidrodinâmico e medidos nas Estações

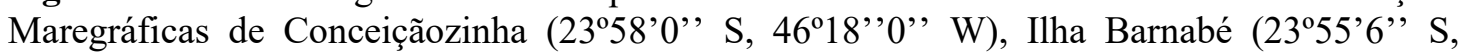
$46^{\circ} 20^{\prime}$ ' 0 ' W) e COSIPA (2352' '4' S, 46 $22^{\prime}$ ' 6 ' W), ao longo do Canal do Porto de Santos. 


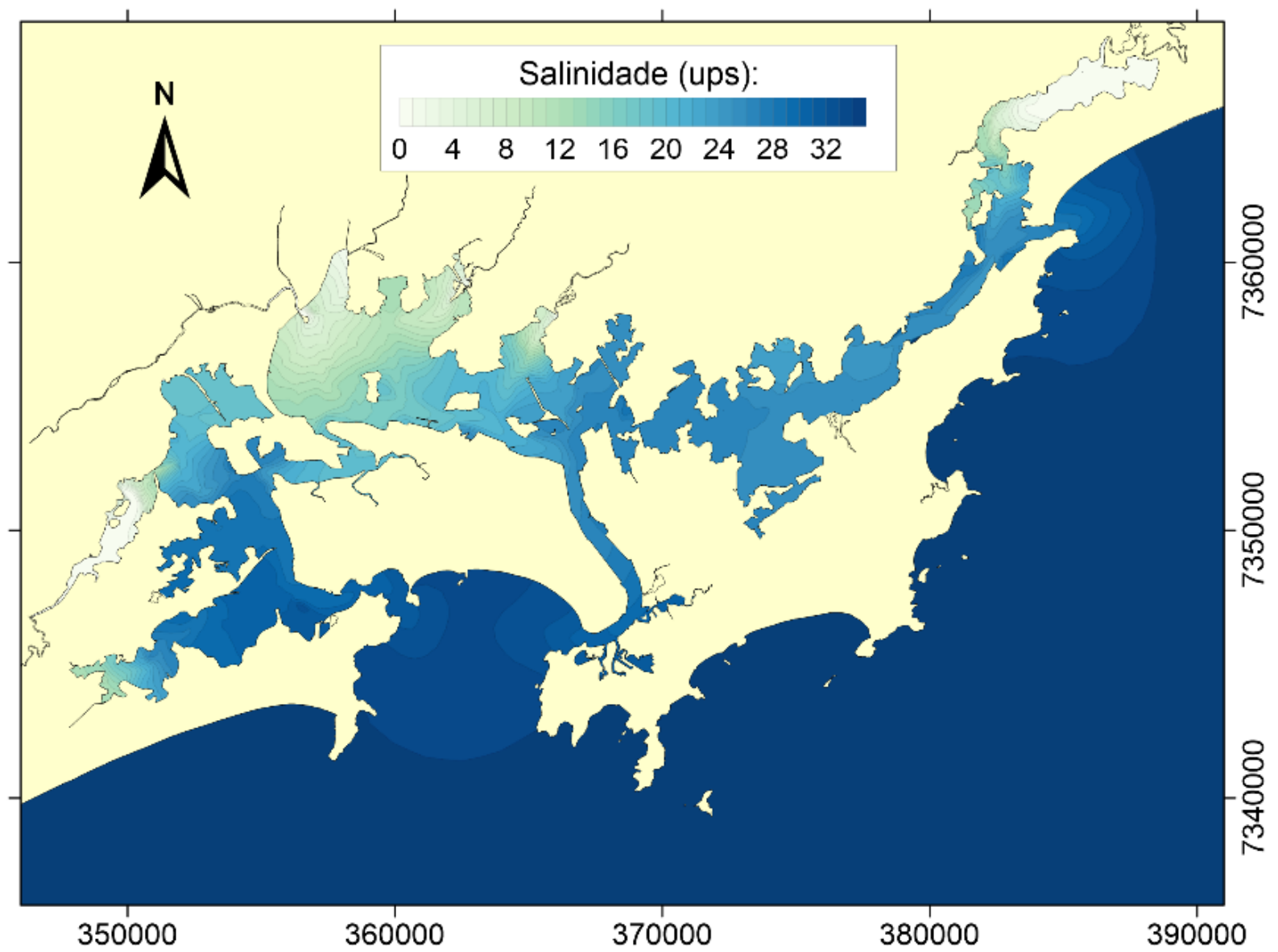

Figura 9. Mínima intrusão salina (período representativo de verão).

\subsection{Modelo hidrodinâmico do Sistema Estuarino de Santos}

Os resultados das simulações hidrodinâmicas permitiram a representação da circulação existente na região de interesse, a partir das velocidades médias na coluna d'água calculadas pelo modelo. Como exemplos são apresentados nas Figuras 10 e 11 os padrões de correntes em instantes de meia maré de enchente e de meia maré de vazante, respectivamente, para o período de sizígia do cenário representativo de verão. Os vetores indicam a direção e a intensidade do escoamento no dado instante, sendo que escala de cores auxilia a visualização da intensidade (módulo da velocidade).

O Canal do Porto de Santos apresenta, em todos os instantes, as velocidades mais intensas de todo o domínio. Na região próxima à sua embocadura as velocidades chegam até $1,4 \mathrm{~m} \mathrm{~s}^{-1}$ na sizígia e até $0,7 \mathrm{~m} \mathrm{~s}^{-1}$ na quadratura. Durante as marés de quadratura as velocidades dos canais principais (desconsiderando as regiões próximas às embocaduras) alcançam aproximadamente $0,4 \mathrm{~m} \mathrm{~s}^{-1}$. Durante as marés de sizígia as velocidades são mais intensas e apresentam maior variabilidade espacial, alcançando $1,2 \mathrm{~m} \mathrm{~s}^{-1}$ aproximadamente.

As regiões marcadas como "fluxo em meio poroso" correspondem às áreas secas, isto é, no instante mostrado o nível d'água calculado está abaixo da cota do terreno. A Figura 12 apresenta os valores elevação máximos e mínimos calculados pelo modelo. Nota-se que quase todas as áreas do domínio estão alagadas no instante de máxima preamar, enquanto que, no instante de mínima baixa-mar, quase todas as áreas definidas como manguezais e bancos de lama estão secas, isto é, o nível d'água calculado neste instante está abaixo da cota definida para o terreno. 

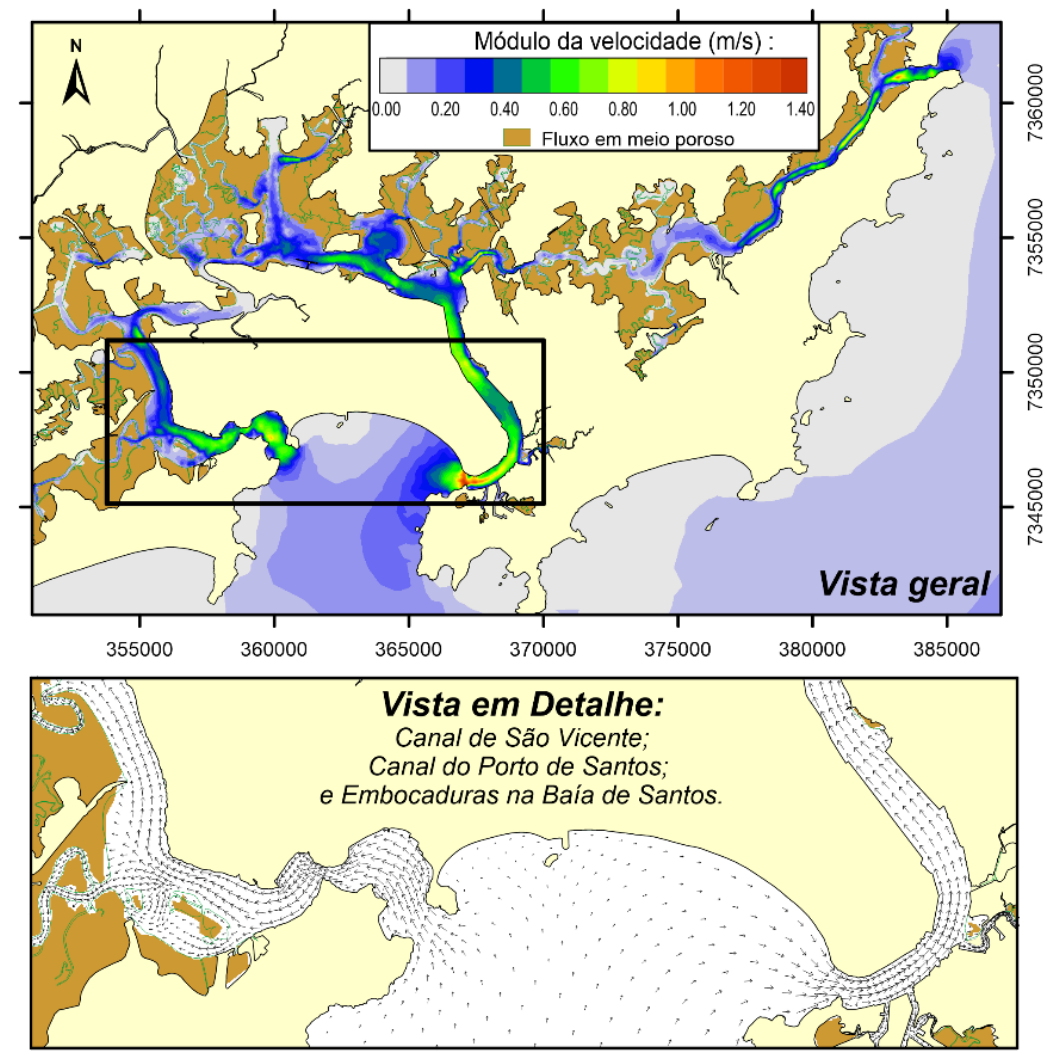

Figura 10. Padrão de correntes em instante de meia maré de enchente (sizígia).
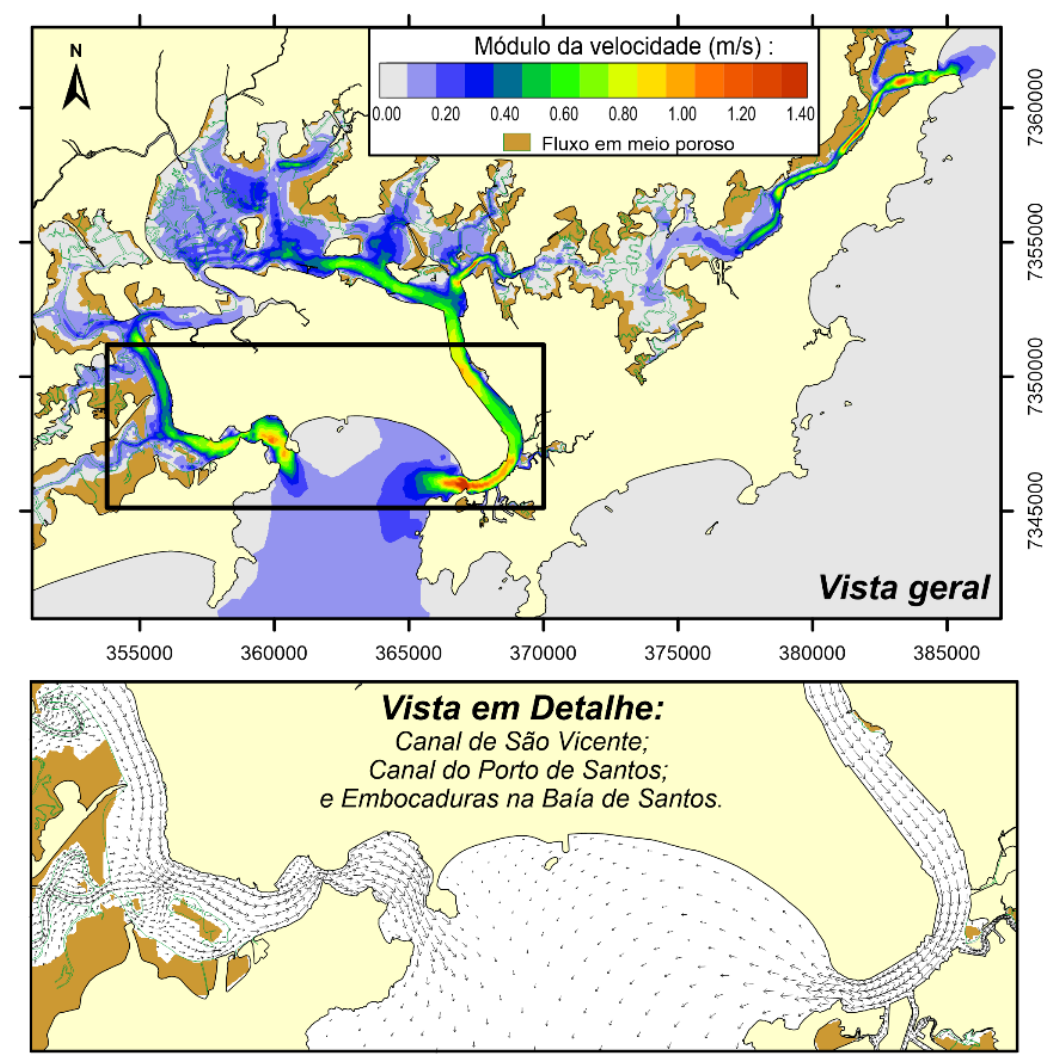

Figura 11. Padrão de correntes em instante de meia maré de vazante (sizígia). 


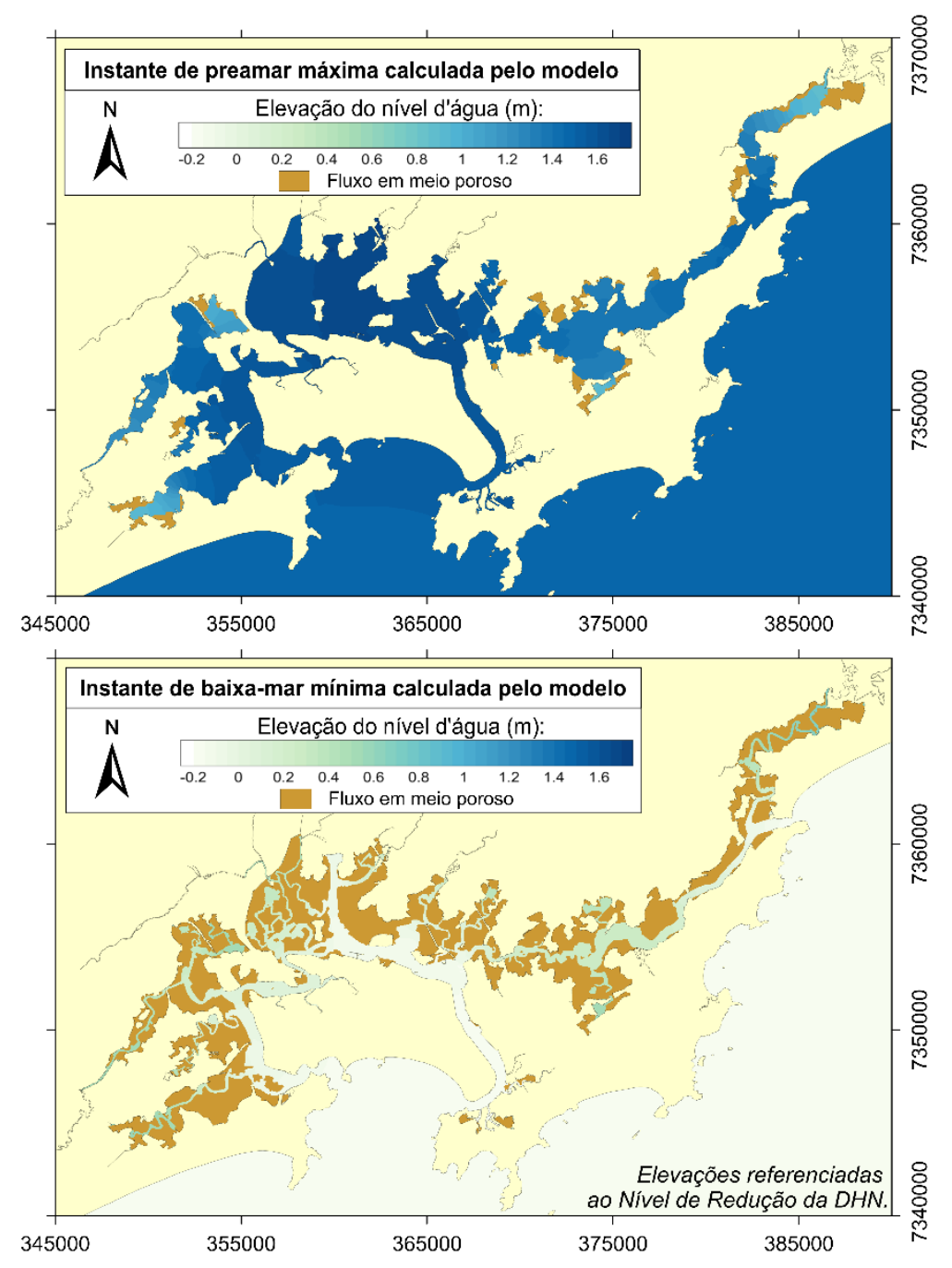

Figura 12. Elevação do nível da água ao longo do domínio em instantes de máxima preamar (acima) e de mínima baixa-mar (abaixo).

\subsection{Taxas de renovação das Águas do Sistema Estuarino de Santos}

A seguir são apresentados os resultados das simulações de transporte Euleriano realizadas para os períodos representativos de verão e de inverno, para análise das taxas de renovação das águas do sistema.

Ao longo das simulações, pelos processos de advecção e de difusão, ocorreram a mistura e a troca da água existente dentro do sistema estuarino na condição inicial com água "nova", proveniente da região costeira e das bacias hidrográficas da região. Os resultados das simulações são apresentados na forma de mapas de isolinhas de renovação e também na forma de séries temporais para estações definidas no modelo.

Os mapas mostram que a renovação ocorre mais rapidamente nas regiões próximas às embocaduras do que nas regiões que recebem diretamente os aportes fluviais (Figura 13). Esse resultado indica a predominância do efeito da maré na renovação e na troca das águas do sistema. Os valores mais baixos de renovação total das águas foram verificados nas proximidades do Rio Santana, a noroeste do Canal Barreiros. Após 15 dias de simulação todo o sistema apresenta uma renovação total maior que 60\%. Após 30 dias todo o sistema apresenta uma renovação total maior que $95 \%$ (Figura 14).

As séries temporais de renovação total mostraram-se, de uma forma geral, semelhantes para o período representativo de inverno e para o período representativo de verão, apresentado 
na Figura 14. Algumas diferenças entre as duas sazonalidades puderam ser verificadas em regiões mais internas e que sofrem maior influência das vazões fluviais afluentes, como por exemplo, no Canal de Piaçaguera. A Figura 15 mostra que no Canal de Piaçaguera, para o período representativo de inverno, são necessários cerca de 22 dias para que haja $90 \%$ de renovação das águas, enquanto que, para o período representativo de verão, são necessários cerca de 17 dias.
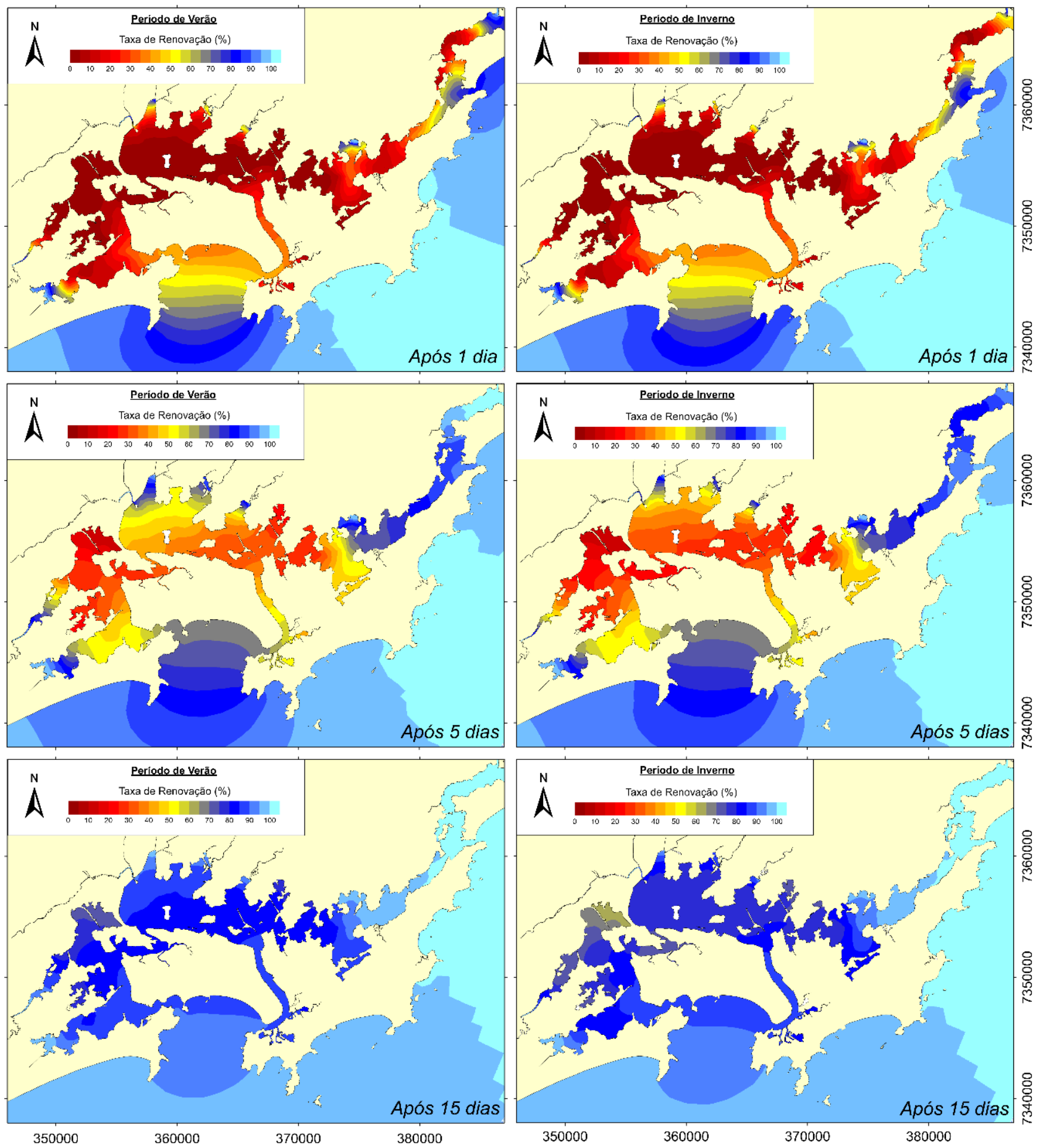

Figura 13. Renovação das águas após um, cinco e quinze dias de simulação (superior, meio e inferior), para os períodos representativos de verão (esquerda) e de inverno (direita). 

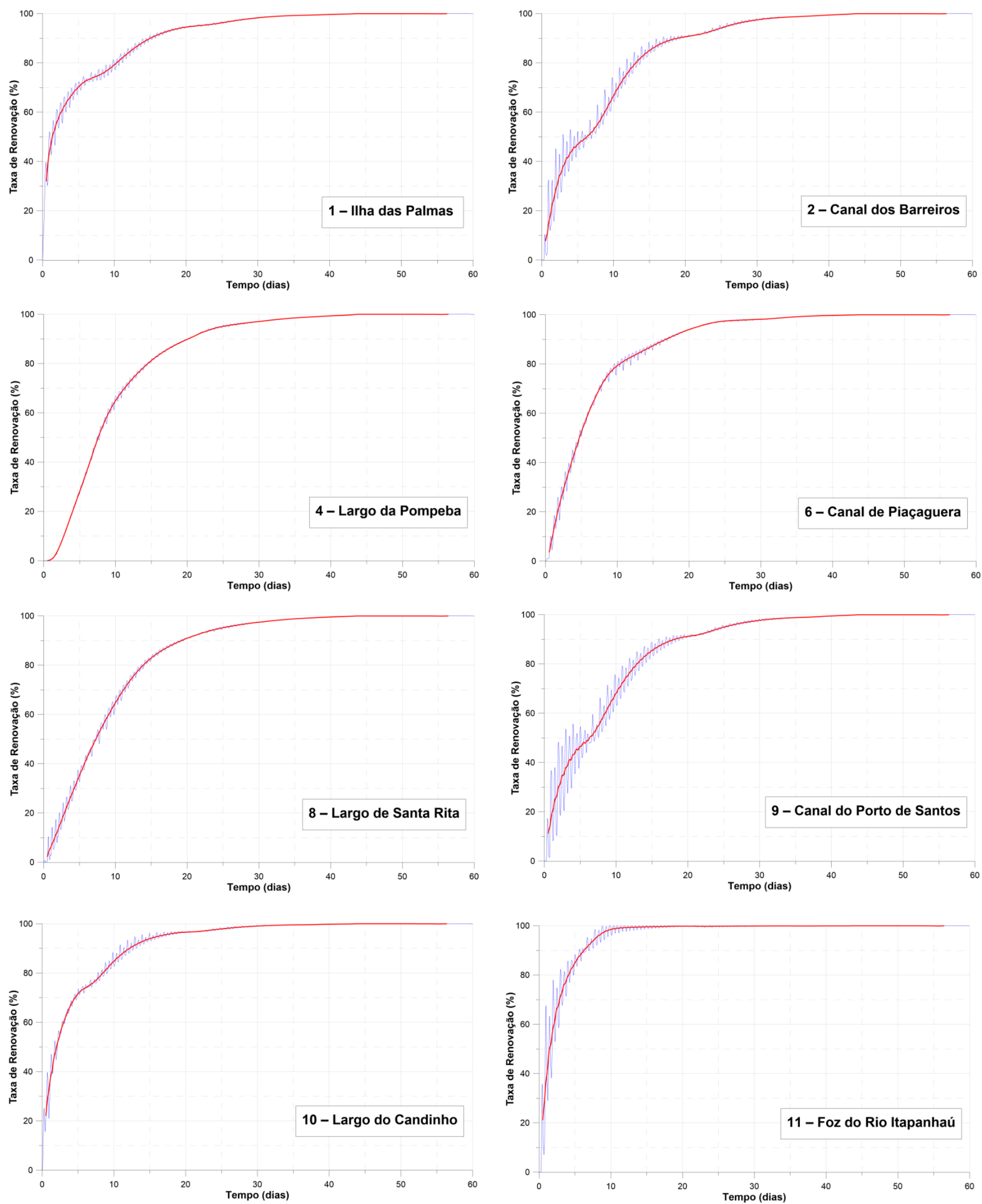

Figura 14. Séries temporais de renovação das águas (linha azul) para o período representativo de verão. Valores apresentados em porcentagem, ao longo de 60 dias de simulação. Linha vermelha representa resultados filtrados, utilizando uma média móvel com período de 24 horas. A localização dos pontos de extração dos resultados pode ser visualizada na Figura 1. 


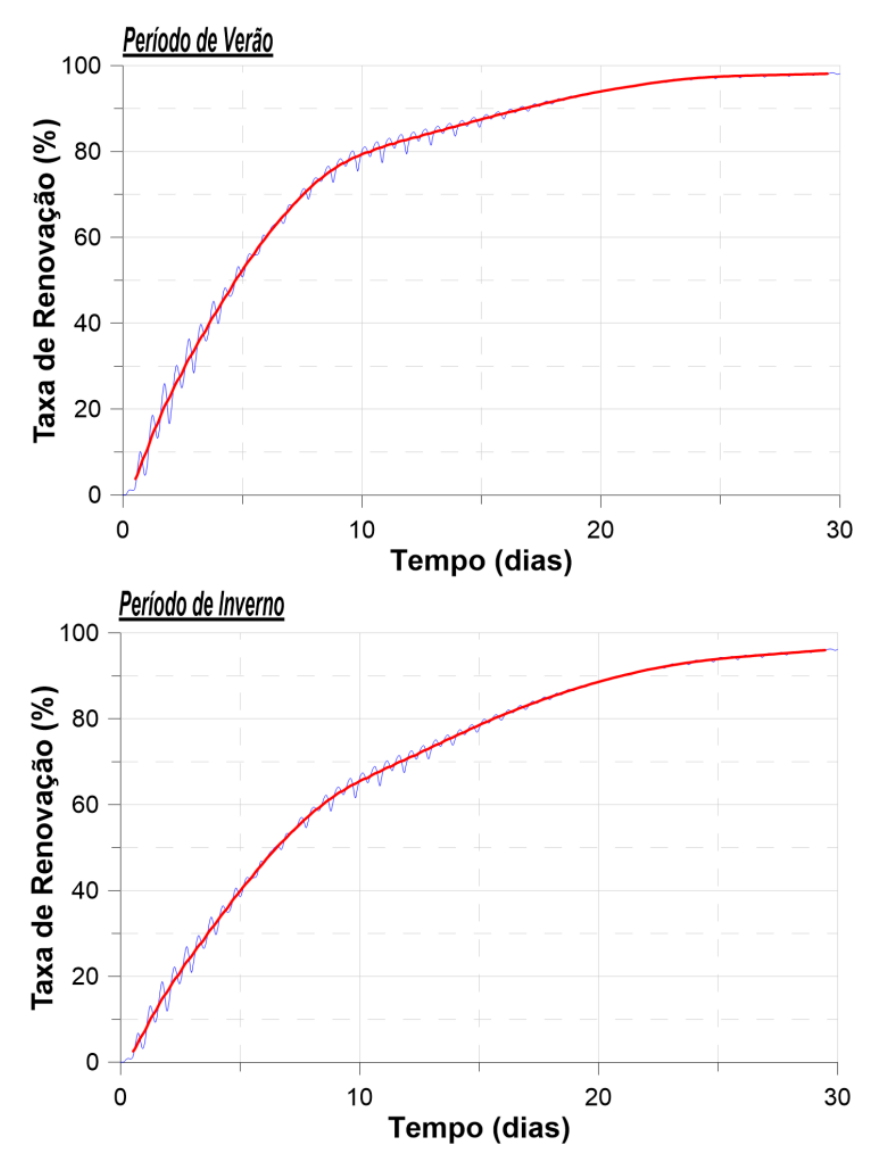

Figura 15. Séries temporais de renovação das águas (linha azul) no Canal de Piaçaguera, nos períodos de verão (acima) e de inverno (abaixo). Linha vermelha representa resultados filtrados, utilizando uma média móvel com período de 24 horas.

\section{CONCLUSÃO}

A aplicação da técnica de modelagem computacional mostrou-se eficaz para a análise da renovação das águas do Sistema Estuarino de Santos. A abordagem utilizada permitiu quantificar a renovação em diferentes posições do sistema e em diferentes intervalos de tempo, tanto na forma de mapas quanto na forma de séries temporais para locais específicos.

As simulações mostraram que águas da Baía de Santos e da embocadura do Canal de Bertioga são mais rapidamente renovadas em relação às regiões localizadas mais a montante do estuário, e.g., Largo de Santa Rita e Rio Santana. Tal constatação se deve ao fato de que há predominância de renovação causada pelo aporte de água proveniente da região costeira, devido ao efeito da maré. Para que haja 95\% de renovação das águas da Baía de Santos, na estação Ilha das Palmas, são necessários aproximadamente 15 dias, ao passo que para o Largo de Santa Rita, região mais interior do sistema, são necessários 20 dias, i.e., 5 dias a mais. Após 30 dias todo o sistema apresenta uma renovação total maior que $95 \%$.

A compreensão da hidrodinâmica deste ambiente complexo é fundamental para o planejamento e o gerenciamento ambiental da região. $\mathrm{O}$ conhecimento do processo de renovação inerente ao sistema permite inferir de forma mais precisa a dinâmica de constituintes presentes em suas águas, de modo a subsidiar ações voltadas para o controle da poluição costeira, para a garantia da saúde pública e também para o aproveitamento de recursos pesqueiros. 


\section{REFERÊNCIAS}

BAPTISTELli, S. C. Análise crítica da utilização de modelagem matemática na avaliação da dispersão de efluentes leves no litoral da baixada santista (Estado de São Paulo). 2008. Tese (Doutorado em Engenharia Hidráulica) - Departamento de Engenharia Hidráulica e Sanitária, Escola Politécnica, Universidade de São Paulo, São Paulo, 2008.

CANTAGALLO, C. Mapeamento de sensibilidade ambiental a derramamentos de petróleo do sistema estuarino de Santos, Estado de São Paulo. 2008. Dissertação (Mestrado) - Instituto de Geociências e Ciências Exatas, Universidade Estadual Paulista, Rio Claro, 2008.

COMPANHIA AMBIENTAl DO ESTAdo DE SÃO PAUlO - CETESB. Programa de Controle de Poluição - Sistema Estuarino de Santos e São Vicente. 2001. Disponível em: http://www.cetesb.sp.gov.br. Acesso em: 11 set. 2015.

COMPANHIA AMBIENTAL DO ESTADO DE SÃO PAULO - CETESB. Relatório de Qualidade das Águas Superficiais no Estado de São Paulo - 2009. São Paulo, 2010. 310 p. Disponível em: http://www.cetesb.sp.gov.br. Acesso em: 11 set. 2015.

CHAMBEL, J.; MATEUS, M. Deliverable 2.3: Calibration of the hydrodynamic model for the Santos Estuary. Lisboa, 2008. Disponível em:

https://www.researchgate.net/publication/238759899_D23. Acesso em: 11 set. 2015.

CENTRO TECNOLÓGICO DE HIDRÁULICA - CTH. Relatório final dos estudos de recuperação e proteção da praia de São Vicente. São Paulo, 1976.

CENTRO TECNOLÓGICO DE HIDRÁULICA - CTH. Relatório das atividades da missão hidrográfica de Santos, para a COPLAT. São Paulo, 1968.

CUNHA, F. P. da. Mapeamento de sensibilidade ambiental a derramamentos de óleo na região costeira de Bertioga - SP. 2009. Dissertação (Mestrado) - Instituto de Geociências e Ciências Exatas, Universidade Estadual Paulista, Rio Claro, 2009.

FUNDAÇÃO DE ESTUDOS DO MAR - FEMAR. Catálogo de estações maregráficas brasileiras. Rio de Janeiro, 2000.

FUNDAÇÃO RICARDO FRANCO - FRF. Estudo de impacto ambiental: dragagem de aprofundamento do canal de navegação, bacias de evolução e berços de atracação do Porto Organizado de Santos. Rio de Janeiro, 2008.

GORDON, M. Modelagem da dispersão de substâncias no Porto e Baía de Santos. 2000. Dissertação (Mestrado) - Instituto Oceanográfico, Universidade de São Paulo, São Paulo, 2000.

GREGÓRIO, H. P. Modelagem numérica da dispersão da pluma do emissário submarino de Santos. 2009. Dissertação (Mestrado) - Instituto Oceanográfico, Universidade de São Paulo, 2009.

HARARI, J.; CAMARGO, R. Modelagem numérica da região costeira de Santos (SP): circulação de maré. Revista Brasileira de Oceanografia, v. 46, n. 2, p. 135-156, 1998. http://dx.doi.org/10.1590/S1413-77391998000200004 
HARARI, J.; CAMARGO, R. Simulação da propagação das nove principais componentes de maré na plataforma sudeste brasileira através de modelo numérico hidrodinâmico. Boletim do Instituto Oceanográfico, n. 42, p. 35-34, 1994. http://dx.doi. org/10.1590/S0373-55241994000100003

INSTITUTO BRASILEIRO DE GEOGRAFIA E ESTATÍSTICA - IBGE. Informações sobre os municípios brasileiros - polução estimada. 2015. Disponível em: http://cidades.ibge.gov.br. Acesso em: 06 abr. 2016.

KALNAY, E.; KANAMITSU, M.; KISTLER, R.; COLLINS, W.; DEAVEN, D.; GANDIN, L. et al. The NCEP/NCAR 40-Year Reanalysis Project. Bulletin of the American Meteorological Society, v. 77, n. 3, 1996. http://dx.doi.org/10.1175/15200477(1996)077\%3C0437:TNYRP\%3E2.0.CO;2

PERINOTTO, R. R. C. Mapeamento de sensibilidade ao derrame de óleo dos ambientes costeiros dos municípios de São Vicente, Santos e Guarujá - SP. 2010. Dissertação (Mestrado) - Instituto de Geociências e Ciências Exatas, Universidade Estadual Paulista, Rio Claro, 2010.

RAGNEV, W. Estudo de potência reativa, tensão, contingência e perdas em empresas de energia elétrica localizadas na grande São Paulo. 2005. Dissertação (Mestrado) Universidade Federal de Uberlândia, Uberlândia, 2005.

RIBEIRO, R. B. Modelagem numérica da influência das fontes de nutrientes sobre a variabilidade da biomassa fitoplanctônica no Sistema Estuarino de Santos-São Vicente. 2012. Dissertação (Mestrado) - Programa de Pós-graduação em Ciência Ambiental, Universidade de São Paulo, São Paulo, 2012.

ROVERSI, F.; ROSMAN, P. C. C.; HARARI, J. Análise das trajetórias das águas continentais afluentes ao sistema estuarino de Santos. Revista Brasileira de Recursos Hídricos, v. 21, n. 1, p. 242-250, 2016.

ROVERSI, F. Estudo hidrodinâmico e de renovação das águas do sistema estuarino de Santos. 2012. Dissertação (Mestrado) - Instituto Alberto Luiz Coimbra de PósGraduação e Pesquisa de Engenharia, Universidade Federal do Rio de Janeiro, Rio de Janeiro, 2012.

ROSMAN, P. C. C. (Org.). Referência técnica do SisBaHiA ${ }^{\circledR}$ - Sistema Base de Hidrodinâmica Ambiental. Rio de Janeiro: COPPE/UFRJ, 2015.

ROSMAN, P. C. C. Subsídios para modelagem de sistemas estuarinos. In: ROSMAN, P. C. C.; ALMEIDA, A. B.; EIGER, S. Métodos numéricos em recursos hídricos. 3. ed. Porto Alegre: ABRH, 1997. p. 238-348.

COMPANHIA DE SANEAMENTO BÁSICO DO ESTADO DE SÃO PAULO - SABESP. Monitoramento da qualidade da água marinha, sedimentos e organismos no estuário de Santos e São Vicente e nas zonas litorâneas e adjacentes nos municípios de Bertioga, Guarujá, Cubatão, Santos, São Vicente e Praia Grande. Relatório Final - Fase 1. São Paulo, 2011.

SAMPAIO, A. F. P. Avaliação da correlação entre parâmetros de qualidade da água e socioeconômicos no complexo estuarino de Santos - São Vicente, através de modelagem numérica ambiental. 2010. Dissertação (Mestrado) - Programa de Pósgraduação em Ciência Ambiental, Universidade de São Paulo, São Paulo, 2010. 
SHS CONSULTORIA E PROJETOS DE ENGENHARIA S/S LTDA. Relatório de situação dos recursos hídricos da baixada santista. São Carlos: CBH-BS; DAEE, 2007. 441 p. Disponível em: http://www.sigrh.sp.gov.br. Acesso em: 11 set. 2015.

YASSUDA, E. A. Modelo numérico do transporte de sedimentos no canal principal do estuário de Santos. 1991. Dissertação (Mestrado) - Instituto Oceanográfico, Universidade de São Paulo, São Paulo, 1991.

ZÜNDT, C. Baixada santista: uso, expansão e ocupação do solo, estruturação de rede urbana regional e metropolização. In: CUNHA, J. M. P. (Org.) Novas metrópoles paulistas população, vulnerabilidade e segregação. Campinas: Unicamp, 2006. p. 305-336. 